\title{
The Strategic Thinking on Promoting the Specialized Towns' New-Style Urbanization Construction in Guangdong Province
}

\author{
Min Liu \\ Guangdong Science and Technology Library, Guangzhou, China \\ Email:minzoe@126.com
}

How to cite this paper: Liu, M. (2016) The Strategic Thinking on Promoting the Specialized Towns' New-Style Urbanization Construction in Guangdong Province. Journal of Service Science and Management, 9, 501511.

http://dx.doi.org/10.4236/jssm.2016.96052

Received: July 18, 2016

Accepted: December 11, 2016

Published: December 14, 2016

Copyright $\odot 2016$ by author and Scientific Research Publishing Inc. This work is licensed under the Creative Commons Attribution International License (CC BY 4.0).

http://creativecommons.org/licenses/by/4.0/

\begin{abstract}
Based on the effectiveness and problems of specialized town urbanization construction in Guangdong in the past, this paper analyzes the top-level design perspective and the implementation of specialized towns' new-style urbanization. The inclusions show that good relationship between the government and the market, excellent combination between local urbanization and remote urbanization can effectively promote the specialized towns' new-style urbanization. At the same time, this paper also resolves some cognitive misunderstandings, such as the "urban-rural integration", "equalization of urban and rural public services".
\end{abstract}

\section{Keywords}

Guangdong, Specialized Town, New-Style Urbanization

\section{Introduction}

The level of specialized town urbanization in Guangdong province has significantly increased since China implemented its reform and opening-up policy, with the objective law of the development of urbanization being based upon, the development of industrial cluster innovation as the driving force, the optimization of the ecological environment and the coordinated development of urban and rural areas being fundamental, and the promotion of the level of economic and social development as the goal. In addition, the role of specialized town in the province's economic and social development has become increasingly prominent; urban infrastructure and public services have significantly increased, which meanwhile greatly improves the living conditions of urban residents. Gradually a path of specialized town urbanization with Guangdong characteristics is created. 


\section{The Differences between Specialized Towns and Industrial Cluster}

Facing with the economic globalization and fierce competitive market, it is difficult for a modern enterprise to obtain the competitive advantages limited by own abilities and resources. The scope of competition has extended from enterprise to cluster. Industrial cluster plays more and more important role in the intellectual economy. There are many successful industrial clusters around the world. Some of them are famous on knowledge intensive business services, such as the famous Central Business District in London, New York, Manhattan and Boston etc. Some are the pools of high technology industrials, like Silicon Valley in America, Bangalore in India, Hsinchu Science and Technology Park in Taiwan and ZhongGuanCun Science and Technology Park in Beijing. Others are the traditional industrial clusters, such as horologe manufacturing industry cluster in Switzerland, furniture industrial cluster in Italy and some industrial clusters in coastal areas of East China. These industrial clusters promote the regional core competence and boost the local economy booming. Industrial clusters are the fountain of competitive advantages.

Guangdong puts accent on specialized towns to develop industrial cluster. In the recent five years, specialized towns are effective in the regional economy development. Gross Regional Product increased to 2.77 trillion·yuan in 2015 from 1.64 trillion·yuan in 2011 , which accounted for $38.05 \%$ of gross product in Guangdong province from $31.6 \%$. However, there are some distinctions between specialized town and industrial cluster. First, specialized town is a regional social unit, which is composed of society, economy, politics, culture, industries and innovation systems, while industrial cluster only gathers the relative industries together to form the industry and economy unit. Second, specialized town is restrained to locate in the township-level administrative division. On the contrary, industrial cluster is more flexible. Smaller district or higher administrative division like provinces can form the industrial cluster. It is not restricted by the geographic space. Third, more than one industry gather into the specialized town, but industrial cluster usually only specialized in one industry. Namely, specialized town is a pool of different industrial clusters. Forth, at the early state of specialized town, the relationships among the enterprises are relatively loose. Interaction among enterprises in the specialized town will be more frequent in the high-speed development period and in latter maturation period. However, enterprises in the industrial cluster keep interacting frequently at the beginning. Moreover, the town government not only acts as a night watchman in the economic development of specialized town but also promotes the transformation and upgrading of specialized town and implements the strategy of innovation-driven development.

\section{The Concept of New-Style Specialized Town}

Establishing the New-style specialized town is one the strategic decision made on the 18th Party Congress of Chinese Communist Party. Population explosion in cities and urban area expansion should not be viewed as the destination of the new-style specialized 
town. To implement the change from countryside to city should focus on industrial structure, employment, residential environment, social security and so on. The changes on policy of state owned land and environment and the disappearance of resource advantage challenge the development of new-style specialized town.

Adhering to the people-oriented, new-style industrialization as the driving force and the overall consideration as principle, new-style specialized towns should promote the urban modernization, urban cluster, ecological cities and rural urbanization and improve the quality of urbanization. The track of urbanization should be scientific, effective, ecological and harmonious. The new-style urbanization should get out of the trap of focus on expanding the scale of cities. Instead, enhancing the urban culture and public services should be the center of development. The main goal of these works is to construct the towns that are suitable for living [1].

Compared with the traditional urbanization, new-style urbanization puts more emphasis on improving the total quality, instead of emphasizing the scale of cities [2]. China has used to adopt development model of extensive economy for a long time. So the importance of resource saving and environment-friendly development should be recognized. New-style urbanization should not only depend on the central cities to drive the economy development, but also emphasize the city clusters and the collaboration between large-median-small cities and towns to achieve the coordinated development of economy and society. The harmonious integration of urban and rural areas should become the central issue in the new-style urbanization in China.

\section{Effects of Specialized Town Urbanization Are Prominent and the Level of Urbanization Is Increasing}

\section{Industries are developing in cluster, creating an efficient and intensive driving force for urbanization.}

After 15 years of development, the industrial agglomeration effect of specialized towns in Guangdong becomes gradually prominent. By the end of the year 2015, there are a total of 399 specialized towns in Guangdong province that achieve a GDP of 2.77 trillion-yuan, accounting for 38.05 percent of the province's GDP. The industrial output value of those town is 6.361925 trillion-yuan, with 9 of the towns achieving industrial output value of over hundreds of billions-yuan. In terms of the towns that achieved an output value of over billions-yuan, there are 141 of them, which accounts for one third of the total. The number of enterprises above designated size reached 30,300; the average degree of corporate concentration in specialized towns is 1712 per town while that in the Pearl River Delta reaches up to 3222 per town. The development model, "One town, one main industry" has led to the effective concentration of business, showing characteristics of a cluster and specialized industry. Traditional industries in specialized towns (i.e. machinery, hardware, textiles and clothing, appliances, furniture, auto parts, building materials, ceramics, agriculture and others) have gradually discarded extensive epitaxial development model of heavy pollution, high energy consumption and high investment. Rather, the industries are shifting to content-type intensive mode, together 
with emerging industries such as electronic information, industrial design, electronics business, eco-tourism etc.

Modern towns develop with ecological construction, building a green and sustainable pattern of development of urbanization.

The rapid rise of specialized towns in Guangdong province has caused the gradual replacement of the original ways of living and management in rural areas by those of an industrial society. The dominance of modern urban life also gradually formed. In order to consolidate the fruits of development and strengthen the development model, the departments of science and technology at the levels of province, city, county and town organized and implemented a plan to promote the coordinated development of modern towns and ecological construction. At present, more than $90 \%$ of the specialized towns have developed a plan of "one town, one policy" specialized industries ecology and technological innovation. Centered around the common technology demand of some industries (i.e. ceramics, household appliances, molds, machinery, footwear, textile and clothing), the specialized towns developed an industrial technology roadmap that fits themselves. Under the dual role of Forced mechanism of financial crisis and the government introducing innovation elements (i.e. talents, research funds and technology etc.) to enterprises, the enterprises in specialized towns have become more conscious of transformation. The enhancement in the awareness has also help them achieve a great transformation from quantity expansion to quality improvement, from the consumption of material resources to the improved quality of labors, from initial processing trade to possessing its own core technology. In addition, those enterprises also shifted from the extensive, dependent, passive development model to specialized, intensive, branding and international development mode. Guided and supported by the government, cities and the below units have formed a complete and integrated system of transportation, communication, electricity, water supply, gas supply facilities and road network; Meanwhile, the residents' living conditions in urban and rural areas have improved, with the establishment of a lifelong education system, employment security system, medical health care system, social security system and smooth public transportation system. These achievements show that an ecological and sustainable urbanization pattern has formed. For example, Nanzhuang town in Foshan city eliminated backward production capacity in recent years through the implementation of "empty the cage and replace the birds" and "the three old". In the meantime, it strengthens the investment, fosters emerging industries and actively constructs a modern industrial system. After the adjustments, the industrial structure of Nanzhuang has transited from an industry featuring a certain product to three-dimensional multi-industry development. Also, its economic growth mode shifted from being extensive energy-consuming to resourcesaving and environmental-friendly. A number of key projects (i.e. the construction of roads and bridges, electricity, water, hotels, commerce, hospitals and schools etc.) meanwhile enhance the ecological environment in Nanzhuang, which turns the place from a heavily-polluted town to a livable and ecological city.

Grasp the scientific concept of development of urban and rural areas and explore 


\section{a new development model of inclusive urbanization.}

Over the past 10 years, specialized towns in Guangdong province to has attained a profound accumulation in exploring the development of the urban-rural integration and achieved remarkable results in promoting urban and rural development planning, infrastructure, integration of basic public services, promotion of the equal trade in elements of urban and rural areas, and balanced allocation of public resources. The achievements also promoted rural population citizenization and increased peasant farmers' income. For the areas with rich resources, supports are given to pilot in fields such as collective land management and economic transition, which led to the formation of new urban-rural relations (i.e. promoting agriculture through industry, promoting the development of rural areas through urban areas, reciprocity between workers and peasant farmers, and the integration of urban and rural areas). In addition, the integration of urban and rural areas and the construction of key projects have improved the urban-rural association and changed the previous governance philosophy that urban and rural areas should be managed separately. Sustainable service capabilities of information systems in grass-roots levels is significantly enhanced; basic public information service systems in rural areas characterized by public welfare, equalization and full coverage have been established and run in great conditions. Moreover, professional application information service systems such as agricultural e-commerce, animal and plant hospital, IOT (The Internet of Things), rural telemedicine, and rural remote management etc. have set great examples in promoting agriculture modernization and the development of urban-rural integration through nationwide informatization. This contributes to the basic formation of highly informatized Guangdong "digital village" and helps the villages enter the ranks of advanced level of rural informatization. The rate of powering through the entire province, towns and villages has reached $100 \%$. Other than that, the coverage of telephone and cable TV is $100 \%$ while that of the mobile communication network is $99.24 \%$. The internet has covered the families in the entire province. All these establishments have given birth to the urbanization of intensive regional economy and endogenous growth and a development pattern of urbanization full of ecology, wisdom, tolerance and humanity.

Take Meizhou Fuxing street as an example, it on the one hand attracts investments through its popular and advantageous tourism projects and encourage powerful enterprises, organizations and individuals to participate in the development of tourism resources in order to promote the construction of ShenGuang mountain tourism industrial park. On the other hand, it increases environmental protection and optimizes the environment for tourism according to its aim "city is a livable area, village is an ecological park". Considering its own resources and the strength of upper to bottom agencies, the street administration has invested nearly 180 million·yuan, with emphasis on rural living rubbish carriage, the "Restore the Rural Beauty by Cleaning" project, "six chaos" rectification, "Three lanes and two areas" greening project etc. Thanks to those projects, the village environment has significantly improved and attained a score of 90 or above in the monthly special assessment. This makes the street stay on the top of the 
rank in Meizhou city and meanwhile shows a new path for the integration of urban and rural areas.

However, with specialized towns as the handle, there are also some outstanding issues in the process of urbanization construction featured Guangdong characteristics, particularly in the current critical period of transformation and upgrading: some towns are reluctant to change and still remain contingent upon a typical extensive epitaxial patterns, so the speedy development of urbanization is based on "Three Highs". ${ }^{1}$ This in turns results in over-loaded bearing of resources and the environment and low comprehensive benefits of people-oriented new urbanization construction. In short, this is a typical "incomplete" urbanization and "semi-urbanization". Therefore, the transition of propulsion model must be implemented as quickly as possible in the near future. Also, changes are needed for the traditional ideas of urban construction. Moreover, we need to actively explore intensive, harmonious and sustainable urbanization model and follow the path of new-type urbanization featured Guangdong characteristics with a distinctive focus on improving the quality of urbanization and reducing the cost of using resources and the environment. By doing that, we are able to lay a solid foundation for actively creating new urbanization demonstrations.

This paper analyzes the top-level design and implementation of specialized town urbanization construction based upon the reality about the development of specialized town urbanization. In the meantime, this paper resolves some related misunderstandings such as "the integration of urban and rural areas", "equalization of urban and rural public services" etc. in order to provide effective support for the implementation of new-type urbanization after the provincial meeting concerning urbanization.

\section{Relationship between Government and Market}

The difference between specialized town and industrial cluster is that specialized town is located in the township-level administrative division, but industrial cluster is not. The town government not only acts as a night watchman in the economic development of specialized town but also promotes the transformation and upgrading of specialized town and implements the strategy of innovation-driven development. Town government has authority to examine and approve issues about the construction of specialized town urbanization, such as the development and planning of towns, the sitting of specialized industrial parks, the examination and approval of land user, the change in function of land, land use permit, building permit, the construction of infrastructure, re-construction and demolition and so on [3]. Furthermore, town government engages in the capital operation in the construction of specialized industrial parks and new commercial centers and the re-construction of old towns. Town government plays a leading role in constructing specialized towns, which deepens the urbanization. Over the past 30 years, Guangdong province has made great progress on urbanization. At the end of 2012, the urbanization rate increased to $67.4 \%$ from $16.3 \%$ in 1978 . The formation of the Pearl River Delta city cluster and town clusters in the east, west and north of

\footnotetext{
1“Three Highs" include heavy pollution, high energy consumption and investments.
} 
Guangdong province has a great boost to the urbanization. ${ }^{2}$ The urbanization rate in the Pearl River Delta is the highest among four city clusters, reaching $83.84 \%$, which catches up the urbanization level of moderately developed country. The urbanization rates of other regions in Guangdong province, east, west and north, are 59.1\%, 39.7\% and $45.3 \% .^{3}$ Specialized towns play a significant role in advancing urbanization in Guangdong province. While, Europe spent 150 years in increasing the urbanization rate from $10 \%$ to $50 \%$, and in the Latin America, more time was taken, about 210 years [4]. Some officials in specialized towns equate construction of buildings with urbanization. More resources are consumed in constructing new buildings, which doesn't improve new-style urbanization in addition to meet officials' need of achievement. Town government monopolizes the authority to allocate resources so that the market fails in resources allocation, which leads to unbalance in different towns. Although the effect of government on specialized towns' urbanization is not neglected, the disadvantages should not be overlooked. Otherwise, the conflict between government and society and market will become more and more intensive.

Compared to government, market is more efficient in allocating resources, but it is question that if specialized towns' urbanization can been accomplished only depending on market without the aid of government. And the failure in urbanization of Mexico implies that it doesn't make it if towns are urbanized only relying on market, which only leads to the movement of population from poor areas to developed regions. It is not the real urbanization that we expect.

Drawing lessons from failure of other countries in urbanization, it is significant to dispose the relationship between government and market. Regional development disparity is significant in Guangdong province. Some towns are developed, some towns are still relying on traditional agriculture and some towns are in the process of industrialization. So in the process of specialized towns' urbanization, avoiding entirely imitating successful modes in other countries is very necessary. On the basis of actual context of towns and the good relationship between government and market, a suitable strategy for new-style urbanization can been made.

\section{Combination between Local Urbanization and Remote Urbanization}

Urbanization has been put into practice for many years in China. Especially with the reform of economy system going on in 1992, urbanization was supported strongly by government. From 1996 to 2012, the urbanization rate increased to 52.6\% from 30.5\% at $1.38 \%$ a year. The deepening of urbanization profited from the investment in the fixed assets and infrastructure, industrialization and the land development in cities, which advanced the construction of cities and boosted the economic development significantly. But some troubles emerge in the extensive mode of development. Resources ${ }^{2}$ Guangdong launched the new-style urbanization, underlining the interaction with industries and cities to avoid the empty towns. Nanfang Daily, 2014-7-28.

${ }^{3}$ The level of urbanization in Pearl River Delta equals moderately developed countries'. Guangzhou Daily, 2013-11-20. 
and environment are overloaded. Population explosion in cities causes traffic jams and inflation of housing price. Besides, urbanization of population lags behind the land urbanization. There are many problems in urbanization, such as the unbalanced development between rural and urban, imbalance in spatial distribution, imbalance in scale and structure, imbalance in structure of elements, imbalance in "four modernizations" development, imbalance between software and hardware, ecological imbalance and so on [5]. How can we promote the coordinated development of urbanization and strive for green development? The report at 18th Party Congress points out that "We should keep to the Chinese-style path of carrying out industrialization in a new way and advancing IT application, urbanization and agricultural modernization. We should promote integration of IT application and industrialization, interaction between industrialization and urbanization, and coordination between urbanization and agricultural modernization, thus promoting harmonized development of industrialization, IT application, urbanization and agricultural modernization". The top-level design stresses that we should keep on the path of urbanization in a new way. We should promote the coordination among the population, resources, environment and development, overall development between rural and urban, integration between city and countryside, equality of public service between rural and urban and equality of earning and sharing money between rural and urban in order to change the urban-rural dual structure and promote the harmonious development of society.

In this 10 years, taking technological innovation as the main thread, Guangdong focused on the construction of public innovative platforms, the improvement of industrial chains and government-university-industry collaboration, which increased the employment opportunities, settled down people who transferred from rural areas, brought technology innovation talents together and promoted the intensive development of urban economy. In order to stimulate the transformation and upgrading of industries that aimed to adjust the industrial structure and enforce technology innovation abilities, these measures promoted the development of industrial-specialized towns' urbanization and played an important role in strengthening the carrying ability and sustainable development ability, promoting the coordination between rural and urban, and improving the system, mechanism and policies of new-style towns' urbanization. This is defined as Urbanization I by J. Friedman. ${ }^{4}$ Owing to the progress made by industries in specialized towns on technology innovation, capabilities of indigenous innovation are improved gradually in more and more industries. Besides, as the price of human resource rises and the automation of industries is improved, the demand of labors declines year by year, especially to the people who transfer from rural areas. So Population agglomeration effect will weaken gradually, if specialized towns only concentrate on motivating the innovation of technology and ignore the development of modern service ${ }^{4}$ J. Friedman divided urbanization into I and II. Urbanization I includes the agglutination of population and non-agricultural activities in cities with different scales and the transformation from non-urban landscape to urban landscape. Urbanization II is the transmission of urban culture, urban lifestyle and value in rural areas. The new-style urbanization with Chinese characteristics was put forward at 18th Party Congress. It should consist of the Urbanization I and II. 
industries. The software construction will fall behind the hardware construction, causing the lack of humanistic spirit and value connotation. These problems will troubles industrial-specialized towns as well. As for agricultural-specialized towns, the familycentered business model is not suitable for the modern market economy with transformation and upgrading of economy and society. The large-scale, intensive and commercialized agriculture production and operation mode will be the trend in agricultural-specialized towns. This trend becomes more and more evident and the economics of scale in modern agriculture is emerging gradually. Meanwhile, the increasing of agricultural surplus labor leads to the transfer from rural to urban frequently. According to the 2012 report on the development of mobile population of China, the number of migrants from rural to urban was 211 million. The scale of mobile population between cities and towns that is smaller than the former, is about 70 million. It is said that excepting for the small towns in the big cities, great majority are not enough attractive for middle classes to live. These small towns are only choice of travel [6]. As for tourismspecialized towns, specialized tourism can boost the development of relevant service industries, such as transportation, accommodation, catering, commerce and trade, entertainment and so on, which not only promotes the ecology civilization construction in new-style urbanization, but pushes forward the development of green and low-carbon economy. Although tourism on season will stimulate the real estate speculation, the development bubble burst easily when tourism is out of reason. "Ghost towns" will appear frequently.

Therefore, in Guangdong province, we should adopt the strategies suiting the local conditions for new-style urbanization of specialized towns. With the upgrading of industries and adjustment of economic structure in the specialized towns located in the Pearl River Delta metropolitan region, the employment opportunities will be created and more talents get together. So the coordination between hardware and software construction can be improved in the process of new-style urbanization. As mentioned earlier, the urbanization rate is $83.84 \%$ in the Pearl River Delta, but only a few specialized towns have got into the mature phrase of urbanization. Majority are still in the developing period. The local urbanization should be deepened in these specialized towns. In other three regions, specialized towns should enhance the construction of infrastructure, the supply abilities of public production and service and the quality of service. Contrary to the local urbanization of Pearl River Delta, these specialized towns will incline to remote urbanization possibly, because more and more agricultural population will move to Pearl River Delta and Yangzi River Delta from rural.

\section{Conclusion}

Firstly, compared to experiences of urbanization in foreign countries, we know that there are two dynamic mechanisms, market and government. Through the path of urbanization in Europe and America, population and industries assembled in the cities and then dispersed. Although paths among countries are different, the development of urbanization could benefit from market pull. On the contrary, governments dominate the 
development of urbanization in China. So, we use the key word "Develop" to describe the urbanization in Europe and America. "Develop" means that urbanizing is an active process, which is confirmed by their experiences. But in China, the development of urbanization is pushed forward passively by government, which reflects the characteristics of the overall promotion. In the past decade, great progress in urbanization derived from the government pull, so the "pull model" is suiting the local condition for new-style specialized towns' urbanization. Avoiding following the tracks of driving urbanization with man-made cities and investment in real estate, it is necessary to strengthen the market pull on the basis of government push.

Secondly, considering the differences among specialized towns in Guangdong and combining the thought on construction of new-style specialized towns' urbanization, I conclude that the construction of new-style specialized towns' urbanization in Guangdong is affected by necessary conditions and sufficient conditions. Necessary conditions contain location, resources, economy and society. Sufficient conditions consist of innovation of system and mechanism, large and middle cities and the characteristic of specialized towns' economy. Evaluating the conditions equipped by specialized towns, a minority of important towns and central towns can push forward the construction of new-style specialized towns' urbanization in all aspects with sufficient and necessary conditions. Others only have conditions to improve the urbanization in industries of sustainable development.

Thirdly, coordination between rural and urban means that we should emphasize the need to put people first, to encourage industry to support agriculture in return for agriculture's earlier contribution to its development and to encourage cities to support rural areas. The task to balance rural and urban development is that rural residents can share the fruits of development with urban at the same time when completing the building of a moderately prosperous society in all respects and rural residents have equal rights, public service and living conditions. So we have to fully understand the real meaning of "coordination between rural and urban". It is not treated as the projects of changing the countryside into city by constructing buildings, which will do great damage to the historical and cultural heritage of countryside. It is forbidden to change the function of agricultural land for industrialization and urbanization in order to protect natural ecological environment. ${ }^{5}$ In addition, realizing the public service equal between rural and urban indicates that government should roughly fairly provide rural and urban residents with the basic public production and service that suit for economic and society development and reflect the principle of fairness and justice, not meaning that countryside should have the absolutely same public service as cities in order to avert rural financial deficit, surplus of public service facilities, waste of land and so on ${ }^{6}$.

\section{References}

[1] Shan, Z. and Huang, Y. (2013) An Analysis of The Concept, Goals, Contents, Planning ${ }^{5}$ http://baike.baidu.com/subview/1523122/11101380.htm?fr=aladdin ${ }^{6} \mathrm{How}$ to promote the public service equal between urban and rural: An example study of Xianyang City. http://paper.people.com.cn/rmlt/html/2012-08/11/content 1106304.htm?div=-1 
Strategies and Misunderstandings of New Urbanization. Urban Planning Forum, 2, 16-22.

[2] Zhang, H. (2013) Reflection Change of China's Urbanization and Connotation Demands of New Urbanization. Ecological Economy, 11, 83-86.

[3] Li, Q., Chen, Y. and Liu, J. (2012) The Study on "Development Model” of Chinese Urbanization. Social Sciences in China, 7, 82-100.

[4] Cha, H. (2014) Adjust the Position of the Government in the Development of New-Style Urbanization. Exploration and Free Views, 2, 61-64.

[5] Shi, Y. (2013) The New-Style Urbanization and the Development of Small Towns in China. Economic Geography, 7, 47-52.

[6] Wei, R. (2013) Seven Imbalance Problems Should Be Disposed in the Development of NewStyle Urbanization. Economic Review, 7, 12-15.

Submit or recommend next manuscript to SCIRP and we will provide best service for you:

Accepting pre-submission inquiries through Email, Facebook, LinkedIn, Twitter, etc.

A wide selection of journals (inclusive of 9 subjects, more than 200 journals)

Providing 24-hour high-quality service

User-friendly online submission system

Fair and swift peer-review system

Efficient typesetting and proofreading procedure

Display of the result of downloads and visits, as well as the number of cited articles

Maximum dissemination of your research work

Submit your manuscript at: http://papersubmission.scirp.org/

Or contact jssm@scirp.org 